SPECTROSCOPY LETTERS

Vol. 37, No. 3, pp. 235-243, 2004

\title{
Educational Multiwavelength Atomic Emission Spectrometer
}

\author{
Alexander Y. Nazarenko* \\ Chemistry Department, College at Buffalo, State University of New York, \\ Buffalo, New York, USA
}

\begin{abstract}
A simple multiwavelength emission instrument utilizing a commercial grating monochromator, a fiber optic sensor to collect radiation from an acetylene-air flame, and a CCD detector, has been evaluated for pedagogical value in the undergraduate curriculum. Simultaneous determination of $\mathrm{Na}, \mathrm{Li}, \mathrm{K}, \mathrm{Rb}$ at ppb level, and $\mathrm{Ca}, \mathrm{Sr}, \mathrm{Ba}$ at ppm level was achieved. The instrument is affordable, yet suitable for solving real analytical problems. High quality visualization makes the spectrometer a useful educational tool.

Key Words: Atomic emission spectroscopy; CCD detector; Fiber optics; Alkali metals; Alkaline earth metals; Flame spectroscopy; Chemical education.
\end{abstract}

\footnotetext{
*Correspondence: Alexander Y. Nazarenko, Chemistry Department, College at Buffalo, State University of New York, Buffalo, NY 14222, USA; E-mail: nazareay@buffalostate.edu.
} 


\section{INTRODUCTION}

Atomic emission spectroscopy (AES) is one of the most important techniques of elemental analysis. ${ }^{[1]}$ One of its advantages over atomic absorption is the capability for simultaneous multielement analysis. It can be used for the analysis of major components of the sample as well as for trace analysis, because calibration curves are linear over several orders of magnitude. As a result of these advantages AES and especially the inductively coupled plasma (ICP) technique are popular in analytical laboratories. Unfortunately, the high cost of the ICP systems prevents their widespread use in undergraduate laboratories.

Most 4-year colleges had acquired atomic absorption instruments by the year $1990 .{ }^{[2]}$ In contrast, atomic emission spectrometers in the undergraduate laboratory are often limited to simple flame instruments for $\mathrm{Na}, \mathrm{K}, \mathrm{Ca}$ analysis, some of them being homemade devices. ${ }^{[3]}$ Although very helpful for teaching freshman through junior chemistry classes, these instruments do not provide senior students with the necessary skills and they give them an incorrect impression of the advantages of AES. It is possible to use the existing atomic absorption instrument in an emission mode. Unfortunately, this approach does not offer our students additional proficiency because of absence of the multielement advantage of AES and a lack of visualization of the atomic spectra.

Over the past decade, a new generation of spectrometer configurations based on charge coupled device (CCD) detectors has appeared. ${ }^{[1,4]}$ Some of them are simple and low-cost. As an example, a multielement atomic absorption instrument has been proposed ${ }^{[5]}$ and a design of a Raman spectrometer has been described. ${ }^{[6]}$ In this paper, we suggest the use of a CCD-based spectrometer in combination with the acetylene-air flame source taken from an existing atomic absorption instrument. Two spectrometer units with different resolutions (FWHM of 1.4 and $0.4 \mathrm{~nm}$ ) were tested.

\section{EXPERIMENTAL}

We employed a Smith-Hieftje 11 atomic absorption instrument (Thermo Jarrell Ash Inc.) as a source of the acetylene-air flame and for the sample introduction. No modifications of the atomic absorption spectrometer were made. It was possible to use the instrument in its usual atomic absorption mode as well as in an atomic emission mode during the same class period.

The CCD spectrometer units were models numbers PC2000 $(200-850 \mathrm{~nm}$, $25 \mu \mathrm{m}$ slit, 600 lines $\mathrm{mm}^{-1}$ ) and HR2000 (500-950 nm, $5 \mu \mathrm{m}$ slit, 600 lines $\mathrm{mm}^{-1}$ ), both from Ocean Optics Inc. An optical fiber with a field of view of about $25^{\circ}$ was placed at a safe distance from the flame (around $5 \mathrm{~cm}$ ) in order to collect and transfer light to the spectrometer unit. The integration 
time was adjusted in an interval from $20-500 \mathrm{~ms}$. The results of at least five readings were averaged. The Ocean Optics data acquisition software, OOIBase 32, was employed for preliminary viewing and real time assessment of the raw data. No correction of the CCD sensitivity was made. The data files obtained were saved in ASCII format and processed using Microsoft Excel ${ }^{\circledR}$ and/or Origin 6.1 (Microcal Software, Inc.). Double deionized water $(>15 \mathrm{M} \Omega$, Barnstead EASYpure LF) was used for the preparation of all solutions. Standard solutions of $\mathrm{LiCl}, \mathrm{NaCl}, \mathrm{KCl}, \mathrm{RbCl}, \mathrm{CsCl}, \mathrm{CaCl}_{2}, \mathrm{SrCl}_{2}$, and $\mathrm{BaCl}_{2}\left(1 \mathrm{~g} \mathrm{~L}^{-1}\right)$ were prepared from reagent grade chemicals. As a result of the high intensity of the appropriate emission lines, the $\mathrm{Na}$ and $\mathrm{K}$ impurities were clearly visible in the atomic spectra of $\mathrm{Sr}$ and Ba salts. More dilute solutions were prepared daily. The calibration solutions as well as the samples were made in $50-\mathrm{mL}$ volumetric flasks and aspirated at a rate of $5 \mathrm{~mL} \mathrm{~min}^{-1}$.

\section{RESULTS AND DISCUSSION}

\section{Alkali Metals Determination with CCD Spectrometer}

Lithium showed a line at $671 \mathrm{~nm}$. The intensity was enough for its determination at $\mu \mathrm{g} \mathrm{L}^{-1}$ level, but still too low for direct lithium assay in natural water. At times, we have used the lithium line as an internal standard to familiarize students with this element.

The sodium doublet $(589.0$ and $589.6 \mathrm{~nm})$, known in spectroscopy as Fraunhofer's D-line, was clearly visible as an absorption line in a solar spectrum (see Fig. 1). As the doublet nature of the sodium line is discussed in numerous textbooks such as Ref. ${ }^{[7]}$, p. 193, it was helpful to resolve this line in an emission spectrum. The $1.4 \mathrm{~nm}$ FWHM of the model PC2000 was not enough for this task, but the HR2000 easily provided the necessary resolution (Fig. 2). It was possible to resolve the asymmetric peak with the data from PC2000 using a gaussian two-peak fit method. Both instruments, of higher and of lower resolution, provided high sensitivity for sodium. The detection limit was at $0.5 \mu \mathrm{g} \mathrm{L}^{-1}$ in our experiments.

The two-peaks of the potassium doublet line at 767 and $769 \mathrm{~nm}$ was clearly visible with the both monochromators tested (Fig. 3). The high abundance of sodium and potassium in laboratory air, and glassware, is the limiting factor for their determination in the students' laboratory. Nevertheless, a detection limit of $4 \mu \mathrm{g} \mathrm{L}^{-1}$ was achieved.

Lines of cesium and rubidium are well separated and the instruments are sensitive enough to detect $5-10 \mu \mathrm{g} \mathrm{L}^{-1}$ quantities, despite the relatively low intensities. There is practically no rubidium or cesium contamination of the laboratory environment. Therefore, higher sensitivity can be easily achieved 


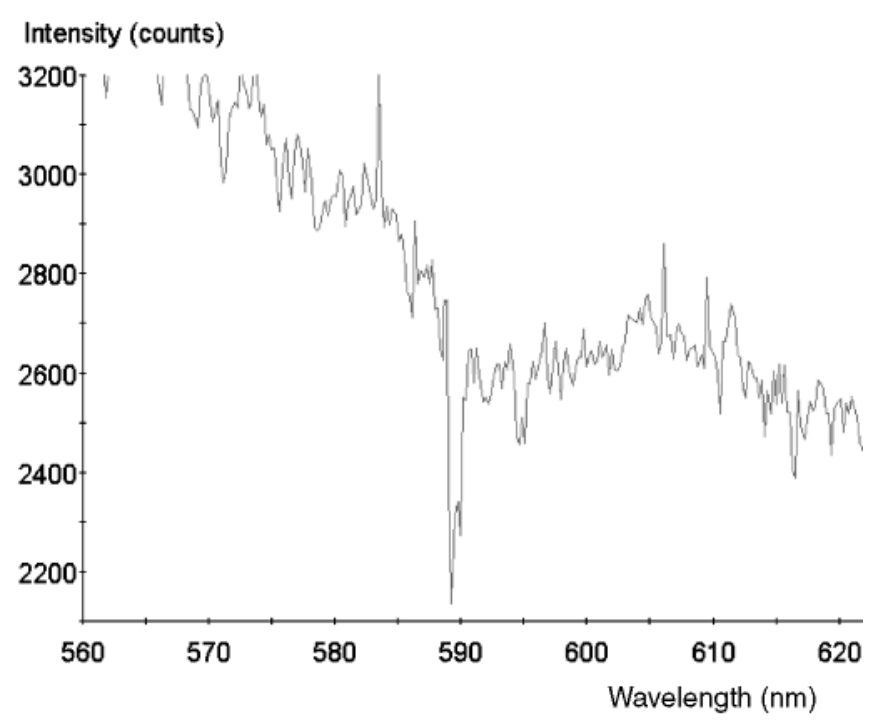

Figure 1. A snapshot of the computer display with the Fraunhofer D-line in the solar spectrum. (View this art in color at www.dekker.com.)

using longer integration times. We have also used cesium chloride as an example of an ionization buffer.

\section{Alkali Earth Metals Determination with CCD Spectrometer}

Both atomic emission lines and molecular emission bands were observed in the flame spectra of $\mathrm{Ca}, \mathrm{Sr}$, and $\mathrm{Ba}$. Determinations of $\mathrm{Ca}, \mathrm{Sr}$, and $\mathrm{Ba}$ are possible with detection limits of $0.05,0.1$, and $4 \mathrm{mg} \mathrm{L}^{-1}$, respectively. The sensitivity of these determinations in the acetylene-air flame was significantly lower than for the alkali metals. These spectra are helpful to demonstrate the nature of spectral interference. For example, the flame emission spectra of $\mathrm{Ba}$ and $\mathrm{Ca}$ show the overlap of the $\mathrm{CaOH}$ molecular emission band with the $\mathrm{Ba}$ resonance line at $553.6 \mathrm{~nm}$ (see Ref. ${ }^{[7]}$ ).

\section{UNDERGRADUATE LABORATORY EXPERIMENTS}

Several undergraduate laboratory experiments and demonstrations were designed. They included a demonstration of a sodium absorption line in sunlight, for a general chemistry course, a laboratory experiment for the qualitative 


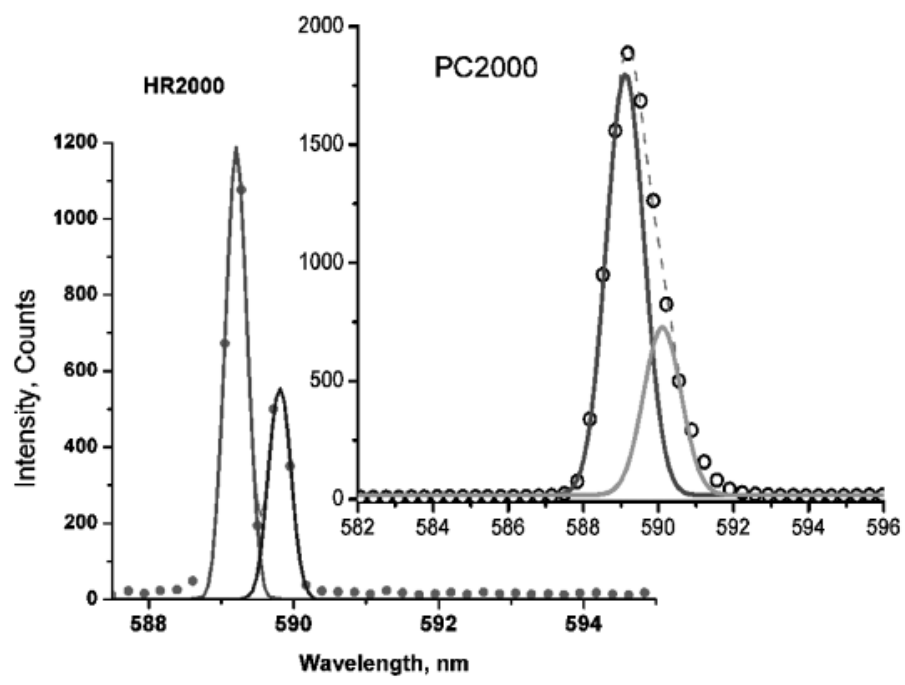

Figure 2. The sodium D-line. Experimental points and a gaussian two-peak fit are shown for both the spectrometers used in the experiments. (View this art in color at www.dekker.com.)

determination of alkali metals in a natural gas flame, and more sophisticated experiments for senior students. OceanOptics *.sample files can be directly opened in Microsoft Excel. The nature of CCD detector is such that the readings corresponding to each wavelength always come from the same element of the detector and, therefore, appear in the same Excel cell. Thus, a small set of Excel formulas can be written to process the experimental data file. These formulas may include functions to read the emission intensities at any wavelength of interest, calculate background correction, and correction by an internal standard as appropriate.

These formulas can be easily prepared by the instructor, while advanced students may write their own set of Excel formulas for data analysis.

\section{Sodium Doublet Line in Sunlight}

The Fraunhofer D-line is clearly visible in the solar spectrum. The students can easily view the split absorption line in the spectrum when they direct the optical fiber of HR2000 towards the laboratory window. It is helpful to compare the results of observation with the emission spectrum of sodium (see the next experiment). The demonstration takes 1-2 min and gives a powerful example of the abilities of spectral analysis; in this case, the possibility of sodium detection in the chromosphere of the sun. 


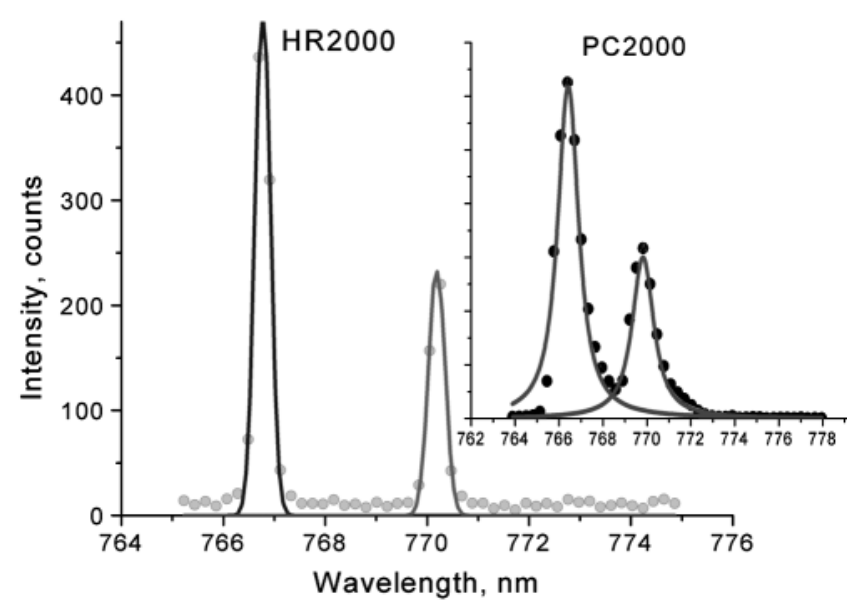

Figure 3. The potassium doublet at $767 / 769 \mathrm{~nm}$. The experimental points and a gaussian two-peak fit are shown for both spectrometers used in the experiments. (View this art in color at www.dekker.com.)

\section{Sodium and Potassium Detection in Aqueous Solution}

This experiment is a part of general chemistry laboratory experiment on qualitative determination of $\mathrm{K}^{+}, \mathrm{Na}^{+}, \mathrm{Ca}^{2+}, \mathrm{Ba}^{2+}, \mathrm{NH}_{4}^{+}$, and $\mathrm{Al}^{3+}$ in solution. $\mathrm{Na}$ and $\mathrm{K}$ emission lines are visible in a natural gas flame. Here, we provide an example of the laboratory instructions for their detection.

\section{Laboratory Instructions for Sodium Detection}

Sodium atoms emit light at $589 \mathrm{~nm}$ that colors the flame yellow. Use a clamp to hold the fiber optic light input in place, and make sure that it is pointing directly at the flame. Dip a wire into the sodium chloride solution and hold it above the burner. The yellow color immediately appears resulting in a doublet peak at $589 \mathrm{~nm}$ visible on the computer display. Remember to save the resultant spectrum. Compare it with the solar spectrum in the vicinity of $590 \mathrm{~nm}$.

Laboratory Instructions for Potassium Detection

Potassium atoms emit light at $404 \mathrm{~nm}$ which tints the flame violet. A much stronger emission line is at $767 \mathrm{~nm}$, and it is easily detectable by the spectrometer. We cannot see this line because it is out of the spectral range 
of human eyes. As before, dip a wire into the test solution and observe the spectrum on the computer display.

The appearance of the 589 and $767 \mathrm{~nm}$ doublet lines in the flame spectrum coming from the unknown solution shows the presence of the corresponding elements.

\section{Sodium, Potassium, and Calcium Determination in Drinking Water}

Water analysis is a typical application of AES. Here, we present a procedure we have been using for the simultaneous determination of $\mathrm{K}, \mathrm{Na}$, and $\mathrm{Ca}$ in drinking water in the instrumental analysis laboratory. Standard solutions of $\mathrm{Na}, \mathrm{K}$, and $\mathrm{Ca}\left(20 \mathrm{mg} \mathrm{L}^{-1}\right)$ were prepared by the instructor before the assay. In this protocol, the addition of ionic buffer (ion suppressant, $100 \mathrm{mg} \mathrm{L}^{-1} \mathrm{Cs}$ and $40 \mathrm{mg} \mathrm{L}^{-1} \mathrm{Li}$ ) is not mandatory; nevertheless, it is helpful because it familiarizes the students with $\mathrm{Li}$ and $\mathrm{Cs}$ spectral lines.

\section{Laboratory Instructions for $\mathrm{Na}, \mathrm{K}$, and Ca Determination}

Prepare the AAS instrument as described in the operating instructions. Set the fiber optic-based spectrometer to the wavelength range from 570 to $800 \mathrm{~nm}$, integration time $20 \mathrm{~ms}$, with averaging of 200 readings. These settings may vary with the instrument. Prepare $1 \mathrm{ppm}$ solutions of $\mathrm{Na}, \mathrm{K}$, and $\mathrm{Ca}$ and measure their emission spectra. Assign appropriate wavelengths for the background and the analyte peak measurements.

Make up a series of six standards by measuring the appropriate volumes of $20 \mathrm{ppm}$ standard solutions into $50-\mathrm{mL}$ volumetric flasks. The resulting concentrations of $\mathrm{Na}, \mathrm{K}$, and $\mathrm{Ca}$ (in $\mathrm{mg} \mathrm{L}^{-1}$ ) should be the following: (1) blank (pure water); (2) $0.040,0.040,0.20$; (3) $0.080,0.080,0.40$; (4) 0.16, 0.16, 0.80 ; (5) $0.32,0.32,1.6$; (6) $0.80,0.80,4.0$.

Add $1 \mathrm{~mL}$ of ionic buffer solution into each of the calibration flasks and dilute to the mark. Measure the emission spectra of these six calibration solutions and process the emission intensities. Estimate the detection limits and the determination limits for $\mathrm{Ca}, \mathrm{Na}$, and $\mathrm{K}$ in water.

To analyze your tap water sample, transfer $2-5 \mathrm{~mL}$ of the sample solution into a 50-mL volumetric flask, add $1 \mathrm{~mL}$ of ionic buffer solution, and dilute to the mark. Measure the emission intensities and calculate the concentrations of $\mathrm{Na}, \mathrm{K}$, and $\mathrm{Ca}$ using the calibration plots.

Repeat your measurements using the standard addition procedure. To do that, transfer the same volume your sample as before, add $1 \mathrm{~mL}$ of ionic buffer solution and appropriate amounts of $20 \mathrm{mg} \mathrm{L}^{-1}$ standards ( $\mathrm{Na}, \mathrm{K}, \mathrm{Ca}$ ), and 


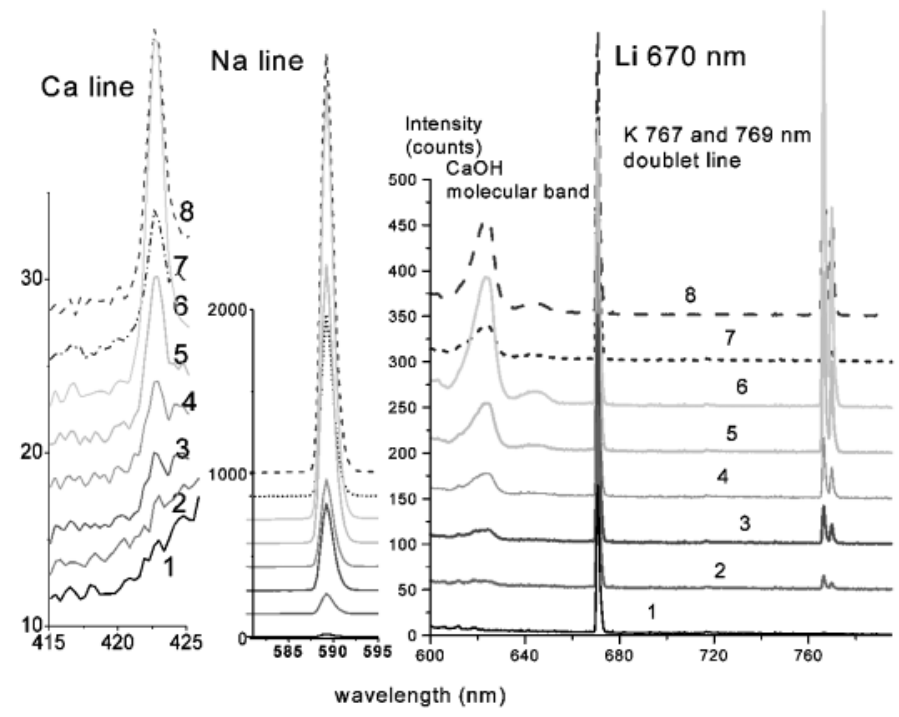

Figure 4. Emission spectra used in drinking water analysis. The spectra correspond to solutions $1-6$ of the calibration (see text), diluted tap water solution (7), and diluted tap water solution with a standard addition (8). PC2000 spectrometer, $20 \mathrm{~ms}$ integration time. (View this art in color at www.dekker.com.)

dilute to the mark. Measure the emission intensities and calculate the amount of $\mathrm{Na}, \mathrm{K}$, and $\mathrm{Ca}$ in your sample using the standard addition formulas. Compare your results with those from the calibration plot.

A selection of spectra used for drinking water analysis is shown in Fig. 4.

Additional experiments at the advanced undergraduate level may include the determination of alkali metals in reagent grade chemicals (for example, in barium chloride), rocks, and in sea water. Corresponding procedures can be easily developed through modification of known methods (see Ref. ${ }^{[8]}$ ). The same fiber opticbased spectrometer is a helpful tool for the demonstration of the emission spectrum of a hollow cathode lamp. While using just one resonance wavelength in an atomic absorption determination, students can see numerous additional lines emitted from the lamp using the CCD spectrometer. This simple demonstration results in a better understanding of the nature of an atomic absorption instrument.

\section{CONCLUSION}

We describe a simple multiwavelength emission device, which is affordable yet suitable for solving real analytical problems. Simultaneous 
determination of $\mathrm{Na}, \mathrm{Li}, \mathrm{K}, \mathrm{Rb}$ at $1-10 \mu \mathrm{gL}^{-1}$ level, and $\mathrm{Ca}, \mathrm{Sr}, \mathrm{Ba}$ at $\mathrm{mg} \mathrm{L}^{-1}$ level was achieved. High quality visualization makes the spectrometer a useful educational tool both for education in general chemistry and at the advanced analytical chemistry level.

\section{ACKNOWLEDGMENTS}

Support from SUNY SCAP 2001 and 2002 grants and from OceanOptics Inc. is gratefully acknowledged. The author thanks Fred Greenberg (SUNY College at Buffalo) and Leeward Bean (OceanOptics Inc.) for reading and commenting on the article.

\section{REFERENCES}

1. Hiefje, G.M. Atomic emission spectroscopy - it lasts and lasts and lasts. J. Chem. Educ. 2000, 77, 577-583.

2. Jones, B.T. Instrumental analysis courses. The choice and use of instrumentation. J. Chem. Educ. 1992, 69, A268-A269.

3. Smith, G.D.; Sanford, C.L.; Jones, B.T. Continuous liquid-sample introduction for Bunsen burner atomic emission spectrometry. J. Chem. Educ. 1995, 72, 438-439.

4. Bernazzani, P.; Paquin, F. Modular spectrometers in the undergraduate chemistry laboratory. J. Chem. Educ. 2001, 78, 796-798.

5. Watson, K.A.; Levine, K.E.; Jones, B.T. A simple, low cost, multielement atomic-absorption spectrometer with a tungsten coil atomizer. Spectrochim. Acta Part B 1998, 53B, 1507-1511.

6. DeGraff, B.A.; Hennip, M.; Jones, J.M.; Salter, C.; Schaertel, S.A. An inexpensive laser Raman spectrometer based on CCD detection. Chem. Educator 2002, 7, 15-18.

7. Skoog, D.A.; Holler, F.J.; Nieman, T.A. Principles of Instrumental Analysis, 5th Ed.; Saunders College Publishing: Philadelphia, 1998.

8. Willard, H.H.; Merritt, L.L.; Dean, J.A. Instrumental Methods of Analysis, 3rd Ed.; Van Nostrand Co.: Princeton, 1958.

Received September 3, 2003

Accepted November 23, 2003 


\section{Request Permission or Order Reprints Instantly!}

Interested in copying and sharing this article? In most cases, U.S. Copyright Law requires that you get permission from the article's rightsholder before using copyrighted content.

All information and materials found in this article, including but not limited to text, trademarks, patents, logos, graphics and images (the "Materials"), are the copyrighted works and other forms of intellectual property of Marcel Dekker, Inc., or its licensors. All rights not expressly granted are reserved.

Get permission to lawfully reproduce and distribute the Materials or order reprints quickly and painlessly. Simply click on the "Request Permission/ Order Reprints" link below and follow the instructions. Visit the U.S. Copyright Office for information on Fair Use limitations of U.S. copyright law. Please refer to The Association of American Publishers' (AAP) website for guidelines on Fair Use in the Classroom.

The Materials are for your personal use only and cannot be reformatted, reposted, resold or distributed by electronic means or otherwise without permission from Marcel Dekker, Inc. Marcel Dekker, Inc. grants you the limited right to display the Materials only on your personal computer or personal wireless device, and to copy and download single copies of such Materials provided that any copyright, trademark or other notice appearing on such Materials is also retained by, displayed, copied or downloaded as part of the Materials and is not removed or obscured, and provided you do not edit, modify, alter or enhance the Materials. Please refer to our Website User Agreement for more details.

\section{Request Permission/Order Reprints}

Reprints of this article can also be ordered at http://www.dekker.com/servlet/product/DOI/101081SL120038760 